\title{
Hallazgos clínicos, epidemiológicos y virológicos del primer brote de covid-19 en Medellín, Antioquia, Colombia
}

\author{
Clinical, epidemiological and virological findings of the first covid-19 outbreak in \\ Medellín, Antioquia, Colombia
}

\author{
Achados clínicos, epidemiológicos e virológicos do primeiro surto de coviD-19 em \\ Medellín, Antioquia, Colômbia
}

Carlos Hernando Velásquez Cuadros'; Rita Elena Almanza Payares²; Yury Johana Silva López³

1 Especialista en Epidemiología. Medellín, Colombia. Gobernación de Antioquia. carlosvelasquez2802@gmail.com. ORCID: https:// orcid.org/0000-0001-9176-4361

2 Field Epidemiology Training Program- FETP Avanzado. Medellín, Colombia. Secretaria de Salud de Medellín. rita.almanza@yahoo.es. ORCID: https://orcid.org/0000-0003-1781-6025

3 Magíster en Epidemiología. Bogotá, Colombia. Instituto Nacional de Salud. ysilval@ins.gov.co. ORCID: https://orcid.org/0000-00024080-1369

Recibido: 01/12//2020. Aprobado: 10/08/2021. Publicado: 25/09/2021

Velásquez-Cuadros CH, Almanza-Payares RE, Silva-López YJ. Hallazgos clínicos, epidemiológicos y virológicos del primer brote de Covid-19 en Medellín, Antioquia, Colombia. Rev. Fac. Nac. Salud Pública. 2022;40(1):e344675. Dor: https://doi. org/10.17533/udea.rfnsp.e344675

\section{Resumen}

Objetivo: Caracterizar clínica, epidemiológica y virológicamente el primer brote de COVID-19, a partir del caso primario en Medellín (Colombia), a través de las acciones de vigilancia y control epidemiológico realizadas para su contención. Metodología: Estudio descriptivo retrospectivo. Los casos secundarios se identificaron teniendo en cuenta la definición del protocolo del Instituto Nacional de Salud. La recolección de datos fue obtenida del Sistema de Vigilancia en Salud Pública, la investigación epidemiológica de campo, historia clínica y resultados de laboratorio. Se tuvieron en cuenta patrones clínicos de la enfermedad (signos y síntomas), componentes epidemiológicos (acciones de vigilancia y control de la transmisión) y virológicos (con el uso de la prueba diagnóstica para SARS-CoV-2 y la evaluación de la recuperación virológica). La confirmación de los casos se hizo por técnica de detección diagnóstica de coronavirus Wuhan 2019 por Reverse Transcription Polymerase
Chain Reaction - Real Time, protocolo Charité, Berlín, Alemania 2020, procesadas en e informadas por el Laboratorio Nacional de Referencia del Instituto Nacional de Salud. Resultados: El caso primario de Medellín ingresó al país el 2 de marzo de 2020, procedente de Madrid (España) y fue confirmado el 9 de marzo. Se identificaron 52 contactos estrechos en 9 conglomerados. Las acciones de vigilancia en salud pública permitieron identificar 5 casos relacionados en una fase temprana de la enfermedad. Conclusiones: La caracterización del caso primario en Medellín permitió identificar el primer brote de COVID-19 y orientar las medidas de control epidemiológico, como aislamientos, tomas de muestras, seguimiento a contactos y búsquedas de casos secundarios.

--Palabras clave: brote por el coronavirus de Wuhan, CoviD-19, Medellín (Colombia), vigilancia en salud pública 


\begin{abstract}
Objective: To characterize clinically, epidemiologically and virologically the first outbreak of covid-19, from the primary case in Medellín (Colombia), through surveillance and epidemiological control carried out for its containment. Methodology: Retrospective descriptive study. Secondary cases are identified taking into account the definition of the protocol of the National Institute of Health. Data collection was obtained of the Public Health Surveillance System, research epidemiological field, medical history and results of laboratory. Clinical patterns of the disease (signs and symptoms), epidemiological components (transmission surveillance and control actions) and virological (with the use of the diagnostic test for sars-CoV-2 and the evaluation of virological recovery). The confirmation of the cases was done by the diagnostic detection technique of Wuhan coronavirus 2019 by reverse transcription polymerase
\end{abstract}

Chain Reaction - Real Time, Charité protocol, Berlin, Germany 2020, processed in and reported by the National Laboratory of Reference of the National Institute of Health. Results: The Medellín's primary case entered the country on March 2, 2020, from Madrid (Spain) and was confirmed on March 9. 52 close contacts were identified in 9 clusters. The surveillance actions in public health made it possible to identify 5 related cases in an early phase of the disease. Conclusions: The characterization of the primary case in Medellín seek to identify the first outbreak of covid-19 and guide the epidemiological control measures, such as isolations, intakes of samples, follow-up contacts and case searches secondary.

-Palabras clave: Wuhan coronavirus outbreak, Covid-19, Medellín (Colombia), public health surveillance

\section{Resumo}

Objetivo: Caracterizar clínica, epidemiológica e virologicamente o primeiro surto de covid-19, desde o caso primário em Medellín (Colômbia), por meio das ações de vigilância e controle epidemiológico realizadas para sua contenção. Metodologia: Estudo descritivo retrospectivo. Os casos secundários foram identificados tendo em consideração a definição do protocolo do National Institute of Health. A coleta de dados foi obtida junto ao Sistema Único de Vigilância em Saúde, pesquisa epidemiológica de campo, história clínica e resultados laboratoriais. Foram considerados os padrões clínicos da doença (sinais e sintomas), componentes epidemiológicos (ações de vigilância e controle da transmissão) e virológicos (com uso do teste diagnóstico para sars-CoV-2 e avaliação da recuperação virológica). A confirmação dos casos foi feita pela técnica de detecção diagnóstica de coronavírus Wuhan 2019 por Reação em Cadeia da Polimerase de Transcrição
Reversa - Tempo Real, protocolo Charité, Berlim, Alemanha 2020, processada e relatada pelo Laboratório de Referência Nacional do Instituto Nacional de Saúde. Resultados: O caso primário de Medellín entrou no país em 2 de março de 2020, a partir de Madrid (Espanha) e foi confirmado em 9 de março. 52 contatos próximos foram identificados em 9 clusters. As ações de vigilância em saúde pública possibilitaram a identificação de 5 casos relacionados em fase inicial da doença. Conclusões: A caracterização do caso primário em Medellín permitiu identificar o primeiro surto de covid-19 e orientar medidas de controle epidemiológico, como isolamento, amostragem, acompanhamento de contatos e busca de casos secundários. --Palabras clave: Surto de coronavírus Wuhan, CoviD-19, Medellín (Colômbia), vigilância de saúde pública

\section{Introducción}

El 31 de diciembre de 2019, la Organización Mundial de la Salud (oms) fue informada de casos de neumonía de etiología desconocida en la ciudad de Wuhan, en la provincia de Hubei, China. En estos casos, "las autoridades aislaron un nuevo tipo de virus de la familia $\mathrm{Co}$ ronaviridae el 7 de enero de 2020" [1, p. 1]. El reporte de situación del 30 de enero de 2020 de la oms informaba casos confirmados en 18 países [2], al tiempo que el Comité de Emergencia del Reglamento Sanitario Internacional declaró la situación por el nuevo coronavirus como una emergencia de salud pública de importancia internacional [3]. La enfermedad fue denominada por la
OMS como COVID-19, causada por el nuevo coronavirus severe acute respiratory syndrome coronavirus 2 (SARS$\mathrm{CoV}-2$ ) que, por su rápida propagación a nivel mundial, conduce a la oms a declarar, el 11 de marzo, el estado de pandemia, emitiendo una serie de recomendaciones para que los países activaran y ampliaran sus mecanismos de respuesta a emergencias $[4,5]$.

"El primer caso en la Región de las Américas se confirmó en Estados Unidos el 20 de enero de 2020, y Brasil notificó el primer caso en América Latina y el Caribe el 26 de febrero de 2020" [6, p. 1]. El primer caso de Colombia fue confirmado el 6 de marzo de 2020, en una 
joven procedente de Milán, Italia, y para el 9 de marzo se reportaron 3 nuevos casos en el país, de los cuales uno correspondía al primero de Medellín.

En salud pública, es de interés conocer la dinámica de transmisión del virus, lo que permite diseñar, adaptar e implementar estrategias de vigilancia y control epidemiológico, para disminuir la velocidad de trasmisión y contener el número de casos, con el fin de que estos no superen la capacidad de respuesta local.

Para la vigilancia en salud pública de infecciones por virus respiratorios, el país tiene reglamentado el "Protocolo de vigilancia en salud pública. Infección Respiratoria Aguda (IRA) códigos: 345, 348, 591, 995”, que incluyen las definiciones operativas de casos, acciones individuales y colectivas, y las responsabilidades de los diferentes actores del Sistema General de Seguridad Social en Salud, entre los cuales se encuentran los entes territoriales, las entidades administradoras de planes de beneficio y las instituciones prestadoras de servicios de salud (IPS), para la articulación de las acciones encaminadas a la identificación y notificación oportuna, el manejo clínico y epidemiológico de los casos, y las acciones comunitarias para su prevención y control, entre otras [7].

Este protocolo tiene, entre sus objetivos, "detectar y confirmar la circulación de virus respiratorios en el país, identificar la llegada de virus nuevos al país, identificar oportunamente los cambios inusuales en el comportamiento de la infección respiratoria aguda y así orientar las medidas de intervención, mitigación y control" [7, p. 7]

Ante la alerta por el riesgo de introducción del coronavirus, el INs elaboró un anexo técnico a este protocolo, con base en el cual los sistemas de vigilancia en salud pública locales adaptaron las estrategias de investigación epidemiológica de campo, seguimiento a contactos, toma de muestras en terreno, búsqueda activa institucional y comunitaria, entre otras, con el fin de identificar los nuevos casos [8]. Esta experiencia motivó el desarrollo de este estudio, el cual tuvo como objetivo caracterizar el primer brote de COVID-19, a partir del caso primario en Medellín (Colombia), y describir las acciones de vigilancia y control epidemiológico realizadas para su contención.

\section{Metodología}

Este es un estudio de tipo descriptivo retrospectivo que incluyó la identificación del primer caso confirmado de COVID-19 en Medellín (Colombia) y la aparición de los casos secundarios que conformaron el brote objeto de esta investigación.

Los datos recolectados se obtuvieron utilizando los siguientes instrumentos del Sistema de Vigilancia en Salud Pública del país, que forman parte del sistema de recolección de datos que se diligencian en la acciones rutinarias de atención y de vigilancia en salud pública: "Ficha de notificación para el evento de infección respiratoria aguda por el nuevo coronavirus", a través del cual se recoge información de identificación demográfica, clínica y de laboratorio diligenciada por la IPs que atendió el caso; "Formato de investigación epidemiológica de campo" y "Formato de seguimiento a contactos estrechos", por medio del cual se recolecta información de inicio y evolución de síntomas de las personas expuestas a un caso confirmado durante 14 días siguientes al último contacto con un caso probable o confirmado de COVID-19. Esto formatos fueron diligenciados por el equipo de respuesta inmediata de la entidad territorial, y del cual hizo parte el equipo investigador.

La investigación epidemiológica de campo es una herramienta de la vigilancia en salud pública, mediante la cual se analizaron los factores individuales, familiares, sociales y ambientales que pudieron incidir en la salud de la persona y su entorno. Incluyó variables de tipo descriptivo, dentro de los cuales estuvieron: la identificación de la personas; sus datos demográficos; aspectos clínicos, como antecedentes personales, signos y síntomas, comorbilidades, examen físico; aspectos epidemiológicos, como fechas de inicio de síntomas, periodos de incubación, periodos de transmisibilidad, exposición a otras personas que pudieron afectarse; ambientales, como acceso a servicios públicos, estado de la vivienda, condiciones de hacinamiento, y otras, como el acceso a los servicios de salud, en donde se describió si existían barreras geográficas o por violencia, disponibilidad de alimentos, acceso a servicios públicos, entre otros.

Las definiciones de caso utilizadas fueron las establecidas en el protocolo denominado "Anexo. Instructivo para la vigilancia en salud pública intensificada de casos probables de infección respiratoria aguda grave por nuevo subtipo de coronavirus (2019-nCov)" [8, p. 1] del INS, y se utilizaron para el estudio las descritas a continuación:

Caso probable de infección respiratoria aguda por el nuevo coronavirus leve o moderada: persona que cumpla con al menos una de las siguientes condiciones:

- Historial de viaje a áreas con circulación de casos de enfermedad por nuevo coronavirus 2019 (COVID-19) en los 14 días anteriores al inicio de los síntomas.

- Trabajador de la salud u otro personal del ámbito hospitalario que haya tenido contacto estrecho con caso probable o confirmado para enfermedad por nuevo coronavirus (COVID-19).

- Antecedentes de contacto estrecho en los últimos 14 días con un caso probable o confirmado con infección respiratoria aguda grave asociada al nuevo coronavirus 2019 (COVID-19). 
Y cumpla con al menos dos de los siguientes síntomas: fiebre cuantificada mayor o igual a $38^{\circ} \mathrm{C}$, tos, dificultad respiratoria, odinofagia, fatiga/adinamia [8, p. 4].

Caso confirmado: persona que cumple la definición de caso probable (del presente anexo) y tenga un resultado positivo para nuevo coronavirus 2019 (COVID-19) mediante rt--PCR en tiempo real [8, p. 5]

Caso descartado: persona que cumple la definición de caso probable (del presente anexo) y tenga un resultado negativo para nuevo coronavirus 2019 (COVID-19) mediante rt-PCR en tiempo real [8, p. 5].

Contacto estrecho: la persona que se encuentra a menos de 2 metros de un caso confirmado de COVID- 19 . Este contacto puede ocurrir mientras cuida, viva, visite, comparta un área de espera, se encuentra en el lugar de trabajo o en reuniones con un caso de CovID-19. O una persona que tenga contacto directo, sin protección, con secreciones infecciosas de un caso de COVID-19 (por ejemplo, con la tos o la manipulación de los pañuelos utilizados). O un trabajador del ámbito hospitalario que tenga contacto con caso probable o confirmado de COVID-19. O una persona que viaje en cualquier tipo de transporte y se siente dos asientos, en cualquier dirección, del caso de COVID-19. Los contactos incluyen compañeros de viaje y personal de la tripulación que brinde atención al caso durante el viaje $[8, \mathrm{p} .4]$

Así mismo, se tomó la definición de conglomerado y brote del manual de atención de brotes de ins:

Conglomerado: aumento en el número de casos, sin que este aumento se configure como epidemia [9, p. 3].

Brote o epidemia: es la aparición de más casos de una enfermedad que los esperados en un área dada en un período de tiempo establecido [9, p. 3].

Para el análisis de los datos, se creó una base de datos que incluye información de identificación demográfica y clínica de los casos y contactos estrechos, asociando a cada caso los contactos según el tipo de relación definido en las siguientes categorías: familiares, transporte aéreo, personal de salud o IPS, sala de espera y sociales.

También se hizo un análisis univariado, describiendo frecuencias absolutas y relativas para las variables de tiempo, persona y lugar. Se analizaron los periodos de incubación de los casos, a partir de la fecha de inicio de síntomas y fecha de probable exposición, con sus respectivos intervalos de confianza, tiempo promedio en días de recuperación clínica y virológica de los casos, así como los de sus cadenas de transmisión.

Para el análisis del componente virológico, la Secretaría de Salud tomó dos muestras respiratorias por aspirado nasofaríngeo (ANF), una inicial para la confirmación diagnóstica, y la siguiente, a los 14 días posterior al inicio de síntomas, para evaluar su recuperación virológica, en concordancia con lo establecido en el "Anexo.
Instructivo para la vigilancia en salud pública intensificada de casos probables de infección respiratoria aguda grave por nuevo subtipo de coronavirus (2019-nCov)" [8]. Estas fueron analizadas y procesadas por técnica de detección diagnóstica de coronavirus Wuhan 2019 por Reverse Transcription Polymerase Chain Reaction - (rtPCR) Protocolo Charité, Berlín, Alemania 2020 en el Laboratorio Nacional de Referencia del INS.

\section{Resultados}

El estudio del primer brote en Medellín incluyó 6 confirmados. El caso primario correspondió a una mujer de 50 años, procedente de Madrid (España), que ingresó al país el 2 de marzo, con inicio de síntomas desde el 28 de febrero de 2020, consistente en fiebre subjetiva, tos seca escasa, congestión nasal, dolor pleurítico, malestar general, mialgias, artralgias, cefalea, escalofríos, sudoración nocturna y desaliento. Consultó el 6 de marzo de 2020 en horas de la noche a una institución de salud de Medellín donde, con base en las instrucciones del "Anexo. Instructivo para la vigilancia en salud pública intensificada de casos probables de infección respiratoria aguda grave por nuevo subtipo de coronavirus (2019-nCov)" [8], en el cual el país estableció la línea técnica para el manejo de los casos, le realizaron diagnóstico clínico de infección respiratoria aguda, la clasificaron como caso probable para el nuevo coronavirus, le tomaron muestra para panel viral y por su resultado negativo se procesó PCR-TR para SARS-CoV-2 en el Laboratorio Nacional de Referencia del INS.

El caso fue notificado como probable de manera inmediata por la IPS al ente territorial municipal, quien dispuso un equipo conformado por un médico y una auxiliar de enfermería. Estos efectuaron la investigación epidemiológica de campo el 7 de marzo de 2020, con el objetivo de buscar contactos para identificar nuevos casos y cortar cadenas de transmisión. Esta actividad incluyó la entrevista al paciente y personas cercanas; se indagó sobre la progresión de la enfermedad; se ampliaron los antecedentes de viajes (fechas, itinerarios, actividades realizadas, traslados, escalas, medios de transporte usados); se indagó por los antecedentes personales y las comorbilidades (hipertensión, sobrepeso, diabetes entre otras patologías crónicas), los cuales fueron referidos negativos en el total de casos confirmados. También se establecieron los factores de riesgo, identificando la visita del caso primario a sitios con circulación viral comunitaria en el exterior, no uso de medidas de bioseguridad por parte de la persona sintomática y no adherencia a la recomendación de aislamiento domiciliario. No se identificaron determinantes en salud que pudieran incidir en el incremento de riesgo de infección o complicaciones. 
Con esta información, se efectuó un análisis de los riesgos que pudieran afectar el estado de salud y se definieron las siguientes estrategias de intervención:

- Evaluación clínica de los posibles afectados: actividad que se realizó para identificar signos y síntomas compatibles con la infección.

- Elaboración de la línea de tiempo del caso confirmado: permitió la identificación de contactos estrechos, periodo de incubación y transmisibilidad, con base en el cual se calcularon los tiempos de aislamiento domiciliario.

- Identificación de los expuestos: para definir conductas, como el aislamiento domiciliario, y establecer la evolución de su estado de salud y signos de alarma.
- Toma de muestras: se tomaron muestras respiratorias por ANF a las personas que cumplieron definición de caso de contacto estrecho (personas que permanecieron por más de 15 minutos a menos de 2 metros de distancia). Estas fueron remitidas al Laboratorio Nacional de Referencia para la realización de rt-PCR para SARS-CoV-2.

- Seguimiento telefónico: fue efectuado diariamente por personal sanitario durante 14 días (periodo estimado de incubación), con el fin de evaluar aparición de síntomas o condiciones que sugieran agravamiento del estado de salud.

Con esta información, fueron identificados 9 escenarios o conglomerados, así (véase Figura 1): el primero lo conformaron 7 personas que compartieron vuelo con el caso durante su periodo de transmisibilidad y que se

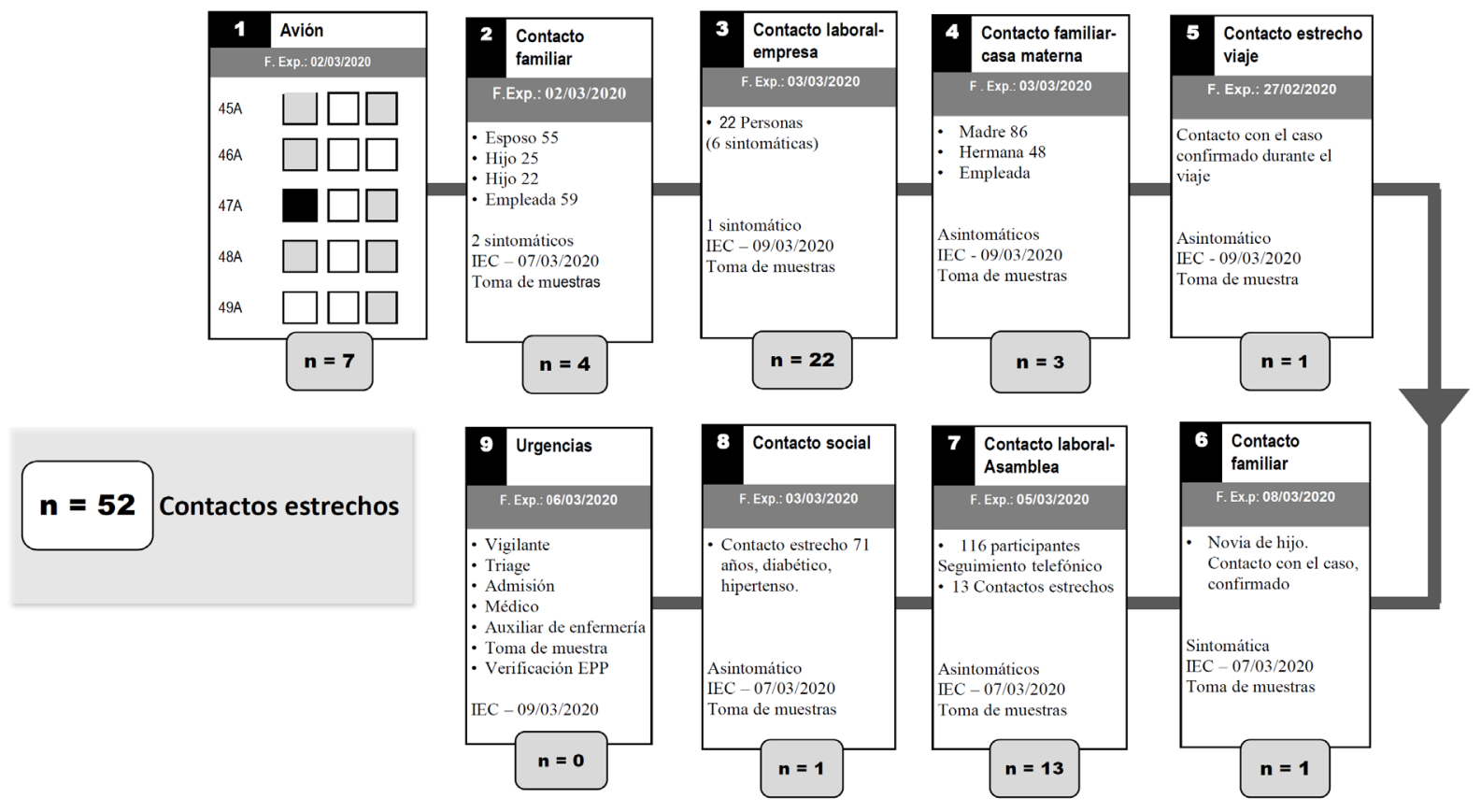

Figura 1. Conglomerados y contactos estrechos del caso primario covid-19, Medellín. $n$ : Número de expuestos; F. Exp.: Fecha de exposición; IEC: Investigación epidemiológica de campo; EPP: Elementos de protección personal

Fuente: Elaboración propia. 
encontraban ubicadas en las sillas adyacentes, las cuales pueden observarse, en la figura, en un tono gris claro; en un tono oscuro, el lugar que ocupó el caso primario durante el vuelo, y en tono blanco, las sillas que se encontraban desocupadas. En este escenario no hubo contactos sintomáticos. Otro conglomerado lo constituyó el grupo familiar, integrado por 4 personas: esposo, dos hijos y empleada de servicio doméstico, quien residía en el hogar. El tercer conglomerado fueron 22 contactos laborales. En el cuarto se identificaron 3 personas residentes en la casa materna. El quinto fue un contacto social. El sexto un contacto familiar. Como séptimo se registró una reunión social, con 13 personas. El octavo fue un contacto social y el noveno fue el conformado por el personal sanitario que atendió el caso, en el que no se encontraron personas expuestas.

El 9 de marzo, el INS reportó el resultado positivo de laboratorio para el nuevo coronavirus (véase Figura 2). En el cerco epidemiológico se identificaron 52 contactos estrechos familiares, laborales y sociales, con 5 casos más confirmados para SARS-CoV-2, con un porcentaje de positividad del 9,4\%.

A partir del caso primario (C1P), se infectaron 3 casos más, 2 correspondientes al núcleo familiar: esposo (C2), hijo (C3), y uno al núcleo laboral (C4). El caso denominado $\mathrm{C} 3$, a partir de una reunión social, infectó dos casos más (C5 y C6). Con las investigaciones epidemiológicas de campo realizadas a los casos probables y sus contactos, se levantaron las líneas de tiempo, identificando periodos de exposición, transmisibilidad, tiempo expectante de aparición de casos secundarios y periodos de incubación, en los cuales se obtuvo un promedio de 3,33 días (IC $95 \%: 1,84-4,82$ ).

El núcleo familiar, conformado por 5 personas que incluye el caso primario-, tuvo una tasa de ataque de $60 \%$, en tanto que la del entorno laboral fue de $4,5 \%$. De los 27 contactos estrechos de uno de los casos secundarios, 2 tuvieron resultado positivo para SARS-CoV-2, con una tasa de ataque del 7,4\%.

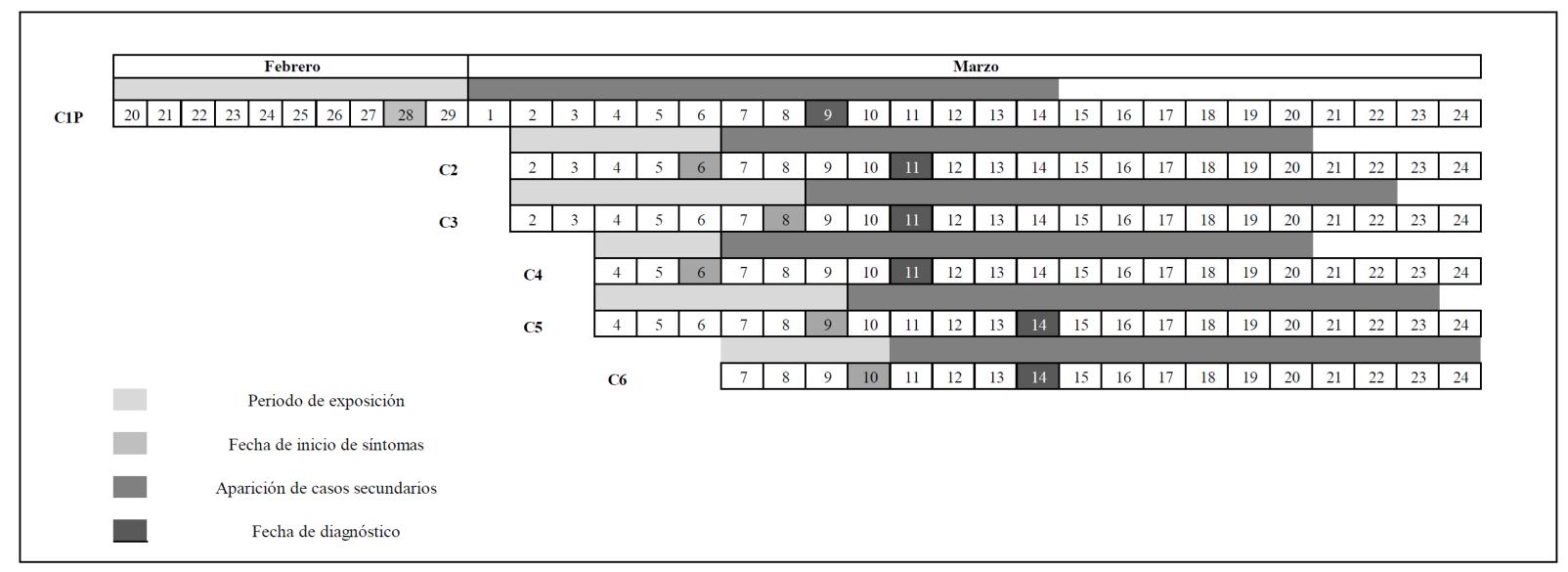

Figura 2. Línea de tiempo. C1P: Caso primario; C2, C3, C4: Casos secundarios; C5, C6: Casos derivados de uno de los casos secundarios

Fuente: Elaboración propia.

Al total de los expuestos se les tomó muestra respiratoria por ANF para RT-PCR, con indicación de aislamiento inicial por dos semanas. En los casos confirmados, el fin del aislamiento se determinó con base en la recuperación virológica, dada por una segunda prueba negativa a los 14 días de iniciado los síntomas. Si la prueba persistía positiva, se procesaba una tercera o cuarta muestra, con intervalo de 7 días entre las tomas. Con este criterio, uno de ellos fue aislado por 28 días.

Los expuestos en seguimiento que presentaron síntomas, como fiebre cuantificada mayor o igual que $38^{\circ} \mathrm{C}$ $\mathrm{y}$ tos, fueron notificados al sistema de vigilancia como caso probable para monitoreo clínico e identificación de signos, síntomas de alarma y rastreo de contactos.

La distribución por sexo fue de $50 \%$. La media de la edad fue de 35,16 años (25-55). El 83,3\% de los casos son residentes en Medellín, y el restante corresponde a un caso domiciliado en Itagüí. El $100 \%$ de los casos fueron en estado leve y ninguno requirió hospitalización.

Se consideró recuperación virológica cuando el control llevado a cabo a los 14 días posteriores a la fecha de inicio de síntomas y procesado a través de rt-PCR tuvo resultado negativo, evidenciando que el promedio de tiempo de recuperación por laboratorio fue de 19,3 días, con un IC $95 \%$ de (14,36-24,31) (véase Tabla 1). 
Tabla 1. Caracterización de los casos del primer brote en Medellín. Semana epidemiológica 11, 2020.

\begin{tabular}{|c|c|c|c|c|c|c|c|}
\hline Caso & Edad & Sexo & Fuente & Estado & Municipio & Fecha inicio síntomas & Fecha recuperación virológica \\
\hline C1P & 50 & Femenino & Importado & \multirow{6}{*}{ Leve } & \multirow{3}{*}{ Medellín } & 28/02/2020 & $15 / 03 / 2020$ \\
\hline C2 & 55 & \multirow{4}{*}{ Femenino } & \multirow{5}{*}{ Relacionado } & & & 6/03/2020 & 26/03/2020 \\
\hline C3 & 25 & & & & & $8 / 03 / 2020$ & 23/03/2020 \\
\hline C4 & 27 & & & & \multirow[t]{2}{*}{ Itagüí } & 6/03/2020 & 26/03/2020 \\
\hline C5 & 26 & & & & & 9/03/2020 & 24/03/2020 \\
\hline C6 & 28 & Masculino & & & Medellín & 10/03/2020 & $10 / 04 / 2020$ \\
\hline
\end{tabular}

Fuente: Elaboración propia.

El síntoma más frecuente que se presentó en esta serie de casos fue la tos, registrada en el $83 \%$ de estos, seguido por otros inespecíficos, como malestar general, rinorrea, escalofríos y cefalea en el $66 \%$. También cobra importancia la odinofagia en el $55 \%$ de los casos, y la fiebre y la fatiga en el $33 \%$ de ellos.

Los síntomas menos frecuentes en esta serie de casos fueron los gastrointestinales y ninguno presentó síndrome de dificultad respiratoria. En escala de gravedad, todos los casos fueron clasificados como leves con manejo sintomático en casa, basado en analgésicos, antipiréticos, líquidos orales y reposo en cama, además de la indicación del aislamiento social. Ninguno requirió hospitalización (véase Tabla 2).

Tabla 2. Descripción de signos y síntomas de casos confirmados del primer brote de coviD-19 Medellín. Semana epidemiológica 11, 2020.

\begin{tabular}{|c|c|c|c|c|c|c|c|}
\hline \multirow{2}{*}{ Signos y síntomas } & \multicolumn{6}{|c|}{ Casos } & \multirow{2}{*}{ Porcentaje (\%) } \\
\hline & C1P & $\mathrm{C} 2$ & C3 & $\mathrm{C} 4$ & $\mathrm{C} 5$ & C6 & \\
\hline Fiebre & $x$ & - & - & - & - & $x$ & 33 \\
\hline Tos & $x$ & - & $x$ & $x$ & $x$ & $x$ & 83 \\
\hline Odinofagia & $x$ & - & - & - & $x$ & $x$ & 55 \\
\hline Fatiga/Adinamia & $x$ & $x$ & - & - & - & - & 33 \\
\hline Síntomas gastrointestinales & - & - & $x$ & - & - & - & 16 \\
\hline Otros & $x$ & - & $x$ & $x$ & - & $x$ & 66 \\
\hline
\end{tabular}

Fuente: Elaboración propia.

\section{Discusión}

Los primeros casos por la COVID-19 en Colombia fueron importados de Italia y España. En el caso de Medellín, su primer caso fue confirmado a los 38 días de haberse declarado la emergencia sanitaria.

Los síntomas presentados por el caso primario fueron: fiebre subjetiva, tos seca escasa, congestión nasal, dolor pleurítico, malestar general, mialgias, artralgias, cefalea, escalofríos, sudoración nocturna y desaliento, con una duración de 9 días, automedicada al inicio del cuadro clínico, lo que pudo haber incidido en la no captación al momento del ingreso al país. Los demás casos confirmados tuvieron predominio de tos y odinofagia, sin antecedente de viaje, por lo que fueron clasificados como relacionados con la importación.
Las manifestaciones clínicas, como fiebre (80-90 \% de los casos) y tos $(50 \%)$, han sido descritas ampliamente [10].

Un estudio llevado a cabo en 138 pacientes en $\mathrm{Wu}$ han reporto fiebre, fatiga y tos como las características clínicas más comunes [11]. Otro estudio realizado en la misma ciudad reportó fiebre y tos en el 83 y $82 \%$ de los pacientes, respectivamente [12]. No obstante, la fiebre y la odinofagia no siempre están presentes y otra variedad de signos y síntomas (en menor frecuencia) han sido reportados.

Una revisión sistemática de la literatura mostró la incidencia de manifestaciones gastrointestinales, como diarrea, dolor abdominal náuseas y vomito, que estuvieron presentes en al menos $10 \%$ de los pacientes por la COVID-19; sin embargo, este porcentaje varió, siendo mayor en estudios fuera de China [13]. Más reciente- 
mente, se han descrito otros síntomas neurológicos, como la disgeusia y la anosmia [14-16].

Este estudio presenta una limitación en la descripción de los síntomas mencionados anteriormente, teniendo en cuenta que pudieron no haber sido referidos, toda vez que estos se empezaron a indagar a medida que la literatura científica fue avanzando en aportar mayor evidencia de la frecuencia de estos en la infección por SARS-CoV-2. Otras variables fueron captadas con mayor facilidad, dado que todos los involucrados cooperaron y entregaron información que permitió contactar los expuestos, favoreciendo acciones que limitaron la propagación del brote.

Los otros brotes registrados en la ciudad no se derivaron del primero. Estos se desarrollaron por el constante ingreso de viajeros procedentes de países con circulación comunitaria del virus; por la subestimación de los síntomas (la mayoría fueron casos leves), similar a lo referenciado en varios estudios descriptivos reportados en la literatura científica, los cuales concluyeron que, en su mayoría, los pacientes confirmados por la COVID-19 tienen un curso clínico con manifestaciones de este tipo (más del $80 \%$ de los casos) [10,11], y por la consulta tardía a los servicios de salud, lo que retrasó la implementación de medidas de control epidemiológico.

Se halló que el tiempo promedio entre la exposición al virus y el inicio de síntomas, conocido como "periodo de incubación" fue, en este estudio, de 3,33 días (IC 95 $\%: 1,84-4,82$ ), similar al reportado por varios autores: Qifang Bi et al. describieron, en su publicación, una mediana del periodo de incubación para COVID-19 de 4 a 8 días (IC $95 \%$ : 4,2-5,4) [17], mientras que Chan et al. estimaron un periodo de incubación entre 3 y 6 días en un conglomerado familiar [18]. Otros estudios reportan periodos de incubación más largos, como en el realizado por Backer, Klinkenberg y Wallinga, quienes concluyeron un promedio de 6,4 días (IC $95 \%$ : 5,6-7,7) [19], ajustándose a los rangos de 1 a 14 días definido por la oms, y de 2 a 14 días, por los Centros para el Control y la Prevención de Enfermedades de Estados Unidos $[10,20,21]$. Los datos del periodo de incubación han sido de gran importancia para determinar los tiempos de aislamiento, estimar los periodos de exposición y orientar el rastreo de contactos, acciones necesarias para el control epidemiológico que impactan directamente en la incidencia de los casos y la letalidad por esta causa.

El total de contactos estrechos del caso primario fue de 52 personas, de los cuales 5 fueron confirmados por laboratorio, para un porcentaje de positividad de la prueba del 9,4\%. Los contactos estrechos del caso secundario fueron 27 , con una tasa de ataque del 7,4 \%.

La transmisión fue favorecida, dado que los síntomas fueron leves y subestimados por los casos al inicio de aquellos. La forma de relacionarse social y laboralmente los casos favoreció la exposición de un número importante de contactos.
En relación con el tiempo de recuperación virológica de los casos, este estudio reportó promedio de 19,3 días (IC $95 \%$ : 14,36-24,31), similar a la de otros estudios, como el realizado en Taiwán, en el que el 69,5\% de los pacientes se recuperaron dentro de las 3 semanas posteriores al inicio de los síntomas y la mediana del tiempo hasta la recuperación fue de 12 días (rango intercuartílico - RIC-, 7-20 días) [22]. Qifang Bi et al. reportaron un tiempo medio de recuperación de 21 días (IC $95 \%$ : 20-22) [17].

Un aprendizaje en el análisis de esta serie de casos fue identificar, como estrategia fundamental para el control de la transmisión, los contactos estrechos, la ampliación de la búsqueda aun a personas asintomáticas y la aplicación de medidas de aislamiento domiciliario, verificado mediante llamadas o visitas al azar durante el posible periodo de incubación, lo que permitió detectar los nuevos casos sin que hubiera nuevos expuestos.

La fase de preparación, que incluyó el monitoreo del comportamiento del SARS-CoV-2 a nivel mundial, las alertas sanitarias y las medidas de prevención comunitarias recomendadas por la OMS, así como la realización de la asesoría técnica al personal sanitario por parte de la Unidad de Epidemiología de la Secretaría de Salud de Medellín, la disposición de personal entrenado en los equipos de respuesta inmediata, la dotación de insumos y la articulación con los diferentes actores de la región, como entes territoriales, unidades primarias generadoras de datos, puertos y aeropuertos, facilitaron la identificación y la contención del primer brote en Medellín.

\section{Agradecimientos}

Los autores agradecen al Centro de Operaciones de Emergencia, conformado por el Instituto Nacional de Salud, la Gobernación de Antioquia y la Alcaldía de Medellín, desde donde se lideraron las acciones para el control epidemiológico.

\section{Financiación}

Ninguna

\section{Conflicto de interés}

Los autores no tienen conflictos potenciales para declarar.

\section{Declaración de responsabilidad}

Lo expresado en el documento es responsabilidad de los autores y no de la Universidad de Antioquia ni de la Revista Facultad Nacional de Salud Pública

\section{Declaración de autoría}

Los autores indicados abajo, certificamos que participamos sustancialmente del trabajo para asumir públicamente la responsabilidad por el contenido. 
Carlos Velásquez Cuadros, 1) Contribuyó substancialmente en la concepción, planeamiento, análisis e interpretación de los datos; (2) En la elaboración del borrador y en la revisión crítica del contenido (3) En la aprobación de la versión final del manuscrito.

Rita Elena Almanza Payares 1) Contribuyó substancialmente en la concepción, planeamiento, análisis e interpretación de los datos; (2) En la elaboración del borrador y en la revisión crítica del contenido (3) En la aprobación de la versión final del manuscrito.

Yury Johana Silva López, 1) Contribuyó substancialmente en la concepción, planeamiento, análisis e interpretación de los datos; (2) En la elaboración del borrador y en la revisión crítica del contenido (3) En la aprobación de la versión final del manuscrito.

\section{Referencias}

1. World Health Organization. Novel Coronavirus (2019-nCoV). Situation Report - 121 January 2020 [internet]; 2020 [citado 2020 may. 21]. Disponible en: https://www.who.int/docs/default-source/ coronaviruse/situation-reports/20200121-sitrep-1-2019-ncov.pdf

2. World Health Organization. Novel Coronavirus ( 2019-nCoV). Situation Report - 10 [internet]. 2020. [citado 2020 may. 21] . Disponible en: https://apps.who.int/iris/handle/10665/330775

3. World Health Organization. Novel Coronavirus ( 2019-nCoV ). Situation Report - 11 [internet]. 2020. [citado 2020 may. 21]. Disponible en: https://apps.who.int/iris/handle/10665/330776

4. Pan American Health Organization, World Health Organization. Actualización epidemiológica: enfermedad por coronavirus - (COvID-19) 20 de abril de 2020 [internet]; 2020 [citado 2020 may. 21]. Disponible en: https://www.paho.org/es/documentos/actualizacion-epidemiologica-enfermedad-por-coronavirus-covid19-20-abril-2020

5. World Health Organization. Coronavirus disease 2019 (COVID-19): Situation Report 51 - 11th March 2020 [internet]; 2020 [citado 2020 may. 21]. Disponible en: https://apps.who.int/iris/ handle/10665/331475

6. Organización Panamericana de la Salud (OPS), Organización Mundial de la Salud (OMs). Respuesta de la ops/oms. 31 de marzo del 2020. Informe N. ${ }^{\circ} 1$ [internet]; 2020 [citado 2020 may. 21]. Disponible en: https://iris.paho.org/bitstream/handle/10665.2/52404/ COVID-19SitRep1_spa.pdf?sequence $=1 \&$ isAllowed $=\mathrm{y}$

7. Instituto Nacional de Salud. Protocolo de vigilancia en salud pública. Infección Respiratoria Aguda (IRA) códigos: 345, 348, 591, 995 [internet]; 2020. [citado 2020 may. 21]. Disponible en: https://www.ins.gov.co/buscador-eventos/Lineamientos/Pro_Infección respiratoria aguda.pdf

8. Instituto Nacional de Salud. (COVID-19), Anexo. Instructivo para la vigilancia en salud pública intensificada de infección respiratoria aguda asociada al nuevo coronavirus 2019.

9. Instituto Nacional de Salud . Dirección de Vigilancia y Análisis del Riesgo en Salud Pública, Grupo de Formación de Talento Humano para la Vigilancia en Salud Pública. Lineamientos para la elaboración de productos GFTH. Lineamientos para la elaboración de productos GFTH - Atención de brotes o emergencias en salud pública [internet]; 2016. [citado 2020 may. 21]. Disponible en:
https://www.ins.gov.co/Direcciones/Vigilancia/Lineamientosydocumentos/Manual de ateción a brotes.pdf

10. Ortiz-Prado E, Simbaña-Rivera K, Gómez-Barreno L, et al. Clinical, molecular, and epidemiological characterization of the SARSCoV-2 virus and the Coronavirus Disease 2019 (COVID-19), acomprehensive literature review. Diagn Microbiol Infect Dis. 2020; 98(1). DOI: https://doi.org/10.1016/j.diagmicrobio.2020.115094

11. Wang D, Hu B, Hu C, et al. Clinical characteristics of 138 hospitalized patients with 2019 novel coronavirus-Infected pneumonia in Wuhan, China. JAmA. 2020;323(11):1061-9. DoI: https://doi. org/10.1001/jama.2020.1585

12. Chen N, Zhou M, Dong X, et al. Epidemiological and clinical characteristics of 99 cases of 2019 novel coronavirus pneumonia in Wuhan, China: A descriptive study. Lancet. 2020;395(10223):50713. DOI: http://dx.doi.org/10.1016/S0140-6736(20)30211-7

13. Sultan S, Altayar O, Siddique SM, et al. AGA Institute rapid review of the gastrointestinal and liver manifestations of COVID-19, meta-analysis of international data, and recommendations for the consultative management of patients with COVID-19. Gastroenterology. 2020;159(1):320-334.e27. DOI: http://dx.doi. org/10.1053/j.gastro.2020.05.001

14. Zahra SA, Iddawela S, Pillai K, et al. Can symptoms of anosmia and dysgeusia be diagnostic for CoviD-19? Brain Behav. 2020;10(1):1-18. https://doi.org/10.1002/brb3.1839

15. Carrillo-Larco RM, Altez-Fernandez C. Anosmia and dysgeusia in COVID-19: A systematic review [versión 1; peer review: 2 approved, 1 not approved]. Wellcome Open Res 2020;5:94. DOI: https://doi.org/10.12688/wellcomeopenres.15917.1

16. Meng X, Deng Y, et al. CovID-19 and anosmia: A review based on up-to-date knowledge. Am J Otolaryngol. 2020;41(5):102581. DOI: https://doi.org/10.1016/j.amjoto.2020.102581

17. Bi Q, Wu Y, Mei S, et al. Epidemiology and transmission of COVID-19 in 391 cases and 1286 of their close contacts in Shenzhen, China: A retrospective cohort study. Lancet Infect Dis. 2020;20(8):911-9. DOI: https://doi.org/10.1016/S14733099(20)30287-5

18. Chan JFW, Yuan S, Kok KH, et al. A familial cluster of pneumonia associated with the 2019 novel coronavirus indicating person-to-person transmission: A study of a family cluster. Lancet. 2020;395(10223):514-23. DOI: http://dx.doi.org/10.1016/S01406736(20)30154-9

19. Backer JA, Klinkenberg D, Wallinga J. Incubation period of 2019 novel coronavirus (2019-nCoV) infections among travellers from Wuhan, China, 20-28 January 2020. Euro Surveillance. 2020;25(5):20-28. DoI: https://doi.org/10.2807/1560-7917. ES.2020.25.5.2000062

20. Organización Mundial de Salud. Preguntas y respuestas sobre la enfermedad por coronavirus (CovID-19) [internet]. s. f. [citado 2020 may. 21]. Disponible en: https://www.who.int/es/ emergencies/diseases/novel-coronavirus-2019/advice-for-public/ q-a-coronaviruses

21. Centers for Disease Control and Prevention. Symptoms of COVID-19 [internet]. s. f. [citado 2020 may. 21]. Disponible en: https://www.cdc.gov/coronavirus/2019-ncov/symptoms-testing/ symptoms.html

22. Sheng W-H, Liu W-D, Wang J-T, et al. Dysosmia and dysgeusia in patients with CoviD-19 in northern Taiwan. J Formos Med Assoc. 2020;120(1 Parte 2):311-7. DoI: https://doi.org/10.1016/j. jfma.2020.10.003 